\title{
Carbon-14 release and speciation during corrosion of irradiated steel under radioactive waste disposal conditions
}

\author{
Typhaine Guillemot $^{\mathrm{a}, 1}$, Gary Salazar ${ }^{\mathrm{b}}$, Martin Rauber ${ }^{\mathrm{b}}$, Dominik Kunz ${ }^{\mathrm{a}}$, Sönke Szidat ${ }^{\mathrm{b}}$, Erich Wieland ${ }^{\mathrm{a}, *}$ \\ ${ }^{a}$ Paul Scherrer Institute, Laboratory for Waste Management, 5232 Villigen PSI, Switzerland \\ ${ }^{\mathrm{b}}$ University of Bern, Department of Chemistry, Biochemistry and Pharmaceutical Sciences \& Oeschger Centre for Climate Change Research, 3012 Berne, Switzerland
}

\section{H I G H L I G H T S}

- Radiocarbon is released during corrosion of irradiated steel in a deep geological repository.

- Speciation of radiocarbon determines its pathways of migration into the environment.

- ${ }^{14} \mathrm{C}$-bearing carboxylates and carbonate are released in the first stage of corrosion.

- ${ }^{14} \mathrm{C}$-bearing methane is the main gaseous ${ }^{14} \mathrm{C}$ carrier.

- The largest portion of the ${ }^{14} \mathrm{C}$ inventory in irradiated steel is released in the gaseous form.

\section{A R T I C L E I N F O}

\section{Article history:}

Received 17 November 2021

Received in revised form 17 December 2021

Accepted 17 December 2021

Available online 25 December 2021

Editor: Frederic Coulon

\section{Keywords:}

Radiocarbon

Accelerator mass spectrometry

Compound-specific radiocarbon analysis

Corrosion

Irradiated steel

Radioactive waste
G R A P H I C A L A B S T R A C T

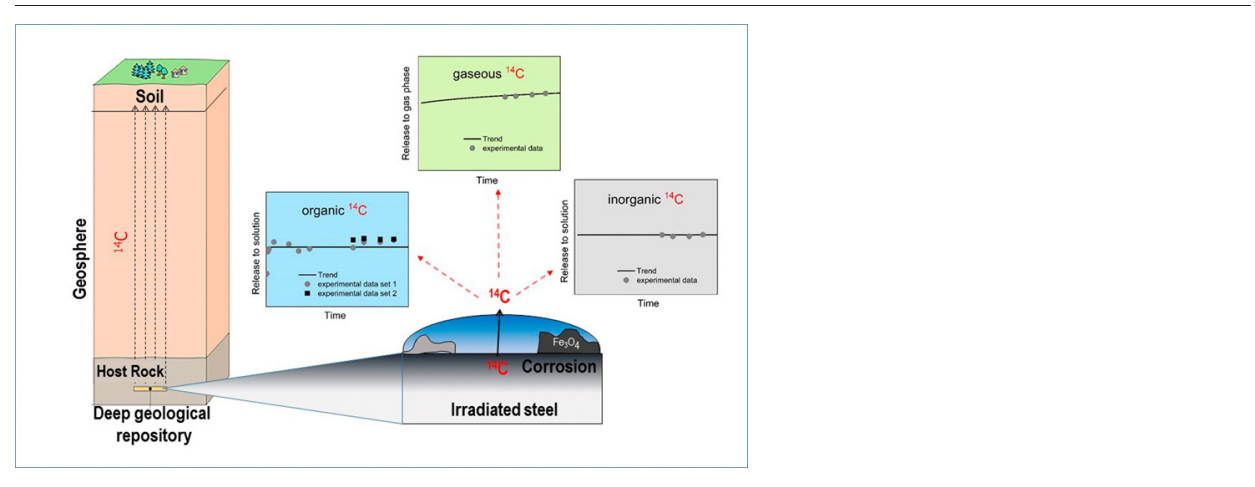

A B S T R A C T

Carbon-14 is a key radionuclide in the safety assessment of deep geological repositories (DGR) for low- and intermediate-level radioactive waste $(\mathrm{L} / \mathrm{ILW})$. Irradiated metallic wastes generated during the decommissioning of nuclear power plants are an important source of ${ }^{14} \mathrm{C}$ after their disposal in a DGR. The chemical form of ${ }^{14} \mathrm{C}$ released from the irradiated metallic wastes determines the pathway of migration from the DGR into the environment. In a long-term corrosion experiment with irradiated steel simulating the hyper-alkaline, anoxic conditions of a cement-based DGR, total inorganic $\left(\mathrm{TI}^{14} \mathrm{C}^{2}\right)$ and organic ${ }^{14} \mathrm{C}$ contents $\left(\mathrm{TO}^{14} \mathrm{C}\right)$ in the liquid and gas phases $\left(\mathrm{TG}^{14} \mathrm{C}\right)$, as well as individual ${ }^{14} \mathrm{C}$-bearing carbon compounds by compound-specific radiocarbon analysis (CSRA), were quantified using accelerator mass spectrometry (AMS). The AMS-based quantification allows the determination of ${ }^{14} \mathrm{C}$ in the pico- to femtomolar concentration range. An initial increase in $\mathrm{TO}^{14} \mathrm{C}$ was observed, which could be attributed partially to the release of ${ }^{14} \mathrm{C}$-bearing oxygenated carbon compounds. In the long term, $\mathrm{TO}^{14} \mathrm{C}$ and the $\mathrm{TI}^{14} \mathrm{C}$ remain constant, while $\mathrm{TG}^{14} \mathrm{C}$ increases over time according to a corrosion rate of steel of $1 \mathrm{~nm} / \mathrm{yr}$. In solution, ${ }^{14} \mathrm{C}$-bearing carboxylic acids (CAs) contribute $\sim 40 \%$ to $\mathrm{TO}^{14} \mathrm{C}$, and they are the main ${ }^{14} \mathrm{C}$ carriers along with ${ }^{14} \mathrm{C}$-bearing carbonate $\left({ }^{14} \mathrm{CO}_{3}^{2-}\right)$. The remaining fraction of $\mathrm{TO}^{14} \mathrm{C}(\sim 60 \%)$ is likely due to the presence of as yet non-identified polymeric or colloidal organic material. In the gas phase, ${ }^{14} \mathrm{CH}_{4}$ accounts for more than $80 \%$ of the $\mathrm{TG}^{14} \mathrm{C}$, while only trace amounts of ${ }^{14} \mathrm{CO}$, and other small ${ }^{14} \mathrm{C}$-bearing hydrocarbons have been detected. In a DGR, the release of ${ }^{14} \mathrm{C}$ will be mainly in gaseous form and migrate via the gas pathway from the repository near field to the surrounding host rock and eventually to the environment.

\footnotetext{
* Corresponding author.

E-mail address: erich.wieland@psi.ch (E. Wieland).

${ }^{1}$ present address: Swiss National Cooperative for the Disposal of Radioactive Waste (Nagra), 5430 Wettingen, Switzerland

${ }^{2} \mathrm{TI}^{14} \mathrm{C}$ : Total inorganic ${ }^{14} \mathrm{C}$; $\mathrm{TO}^{14} \mathrm{C}$ : total organic ${ }^{14} \mathrm{C}$; $\mathrm{TG}^{14} \mathrm{C}$ : total gaseous ${ }^{14} \mathrm{C}$
} 


\section{Introduction}

Carbon-14 $\left({ }^{14} \mathrm{C}\right)$ is a key radionuclide in the safety analysis of deep geological repositories (DGR) for radioactive waste and near-surface facilities (e.g., Nuclear Decommissioning Authority, 2012; Johnson and Schwyn, 2008; Yim and Caron, 2006). Radiological assessments have shown that ${ }^{14} \mathrm{C}$ is an important dose-contributing radionuclide due to its long half-life (5700 years), the high mobility of gaseous and aqueous ${ }^{14} \mathrm{C}$-bearing carbon compounds in the DGR and in the geosphere due to their weak interaction with mineral surfaces under near-neutral to alkaline conditions, and the fact that ${ }^{14} \mathrm{C}$ can be taken up into the human food chain. The Swiss concept for the safe disposal of radioactive waste envisages the storage of low- and intermediate-level waste (L/ILW) in a cement-based DGR at a suitable depth (few hundred meters below the surface) in the Opalinus Clay formation (Nagra, 2014a, 2016). The chemical form of the ${ }^{14} \mathrm{C}$-bearing carbon species determines the pathway of ${ }^{14} \mathrm{C}$ migration in the engineered barrier system (EBS) of the DGR and the surrounding host rock, and is therefore responsible for the long-term contribution of ${ }^{14} \mathrm{C}$ to dose release from the repository (Johnson and Schwyn, 2008; Yim and Caron, 2006). ${ }^{14} \mathrm{C}$ decays if it can be retained in the EBS of the DGR for a sufficiently long time, while radiological consequences may arise when ${ }^{14} \mathrm{C}$ is released in the organic and especially gaseous form. Therefore, knowledge of the ${ }^{14} \mathrm{C}$ species produced during corrosion of irradiated metals is of paramount importance to evaluate the time dependence of ${ }^{14} \mathrm{C}$ release and its dose contribution over the period relevant to a DGR.

The Swiss Model Activity Inventory (MIRAM) identified irradiated steel as the main source of ${ }^{14} \mathrm{C}$ in the existing and future arising $\mathrm{L} / \mathrm{ILW}(\sim 75 \%)$ (Nagra, 2014b). ${ }^{14} \mathrm{C}$ in irradiated steel is primarily produced by the activation of nitrogen impurities contained in fuel assembly components and components of the core structural materials of light water reactors, as a consequence of the ${ }^{14} \mathrm{~N}(\mathrm{n}, \mathrm{p}){ }^{14} \mathrm{C}$ nuclear reaction. The release of ${ }^{14} \mathrm{C}$ occurs during the corrosion of irradiated steel components in the DGR. Very little information is available on the chemical form of ${ }^{14} \mathrm{C}$ during corrosion under strongly alkaline anoxic conditions relevant to a cement-based DGR (de Visser-Týnová et al., 2018; Swanton et al., 2015; Wieland and Hummel, 2015 and references therein). Both oxidized and reduced carbon compounds with a small number of carbon atoms (generally between C1 and C5) have been detected in corroding, non-irradiated iron-water systems in these conditions (Cvetković et al., 2018a; Guillemot et al., 2020a; Wieland and Hummel, 2015). Furthermore, a recent corrosion study using irradiated steel identified dissolved and gaseous ${ }^{14} \mathrm{C}$-bearing small carbon compounds (de Visser-Týnová et al., 2018). In the present study on the corrosion of irradiated steel, we developed analytical methods that allow both oxidized and reduced ${ }^{14} \mathrm{C}$-bearing carbon compounds to be identified and quantified at ultra-low concentrations in both the liquid and gas phases by accelerator mass spectrometry (AMS) (Cvetković et al., 2018b; Cvetković et al., 2018c; Guillemot et al., 2020b). The extremely low ${ }^{14} \mathrm{C}$ concentrations expected in this corrosion experiment are a consequence of the small size and low ${ }^{14} \mathrm{C}$ content of the irradiated steel samples, the extremely slow corrosion of stainless steel under alkaline anoxic conditions, and finally the small sample quantities available for analysis with the given experimental set-up. The AMS-based analytics allowed quantification of total ${ }^{14} \mathrm{C}$ contents in the solution and gas phase and identification of individual ${ }^{14} \mathrm{C}$-bearing carbon compounds by compound-specific radiocarbon analysis (CSRA).

\section{Materials and methods}

\subsection{Solutions and chemicals}

All standard solutions were prepared using chemicals with high purity grade (> 98\%) from Sigma-Aldrich (Buchs, Switzerland), Alfa Aesar (Karlsruhe, Germany) and Merck analytical grade ("pro analysis") (Hohenbrunn, Germany). Ultrapure (deionized, de-carbonated) water (MilliQ ${ }^{\circledR}$ water; 18.2 M $\Omega \cdot \mathrm{cm}$ resistivity), generated by a MilliQ Gradient A10 purification system (Millipore, USA), was used to prepare solutions and sample dilutions. Degassed water was obtained by boiling ultrapure water for $2 \mathrm{~h}$ under continuous $\mathrm{N}_{2}$ purge. The $\mathrm{O}_{2}$ concentration $(<1 \mathrm{ppb})$ was controlled using a PreSens PSt6 planar oxygen sensor (Regensburg, Germany). An artificial cement pore water (ACW) with $\mathrm{pH} 12.5$, used to simulate pore water conditions in the near field of a cement-based DGR and corresponding to a solution saturated w.r.t. $\mathrm{Ca}(\mathrm{OH})_{2}$, was prepared as reported elsewhere (Cvetković et al., 2018c).

\subsection{Irradiated steel}

Two small specimens of irradiated stainless steel with a total mass of $1.718 \mathrm{~g}$, a dose rate of $\sim 20 \mathrm{mSv} / \mathrm{h}$ per gram of steel, and a total surface area of $11.15 \mathrm{~cm}^{2}$ were used for the corrosion experiment (Schumann et al., 2014; Wieland et al., 2018; Wieland et al., 2017). The type of the stainless steel used to fabricate the guide-tube nuts is not exactly known, while there is information from the manufacturer to suggest that the nuts were produced from one of the following alloys: X6CrNiTi18-10 (1.4541), X6CrNiNb18-10 (1.4550) or X6CrNiMoTi17-12-2 (1.4571). The small samples used for the corrosion experiment were prepared from an irradiated steel nut exposed to a thermal neutron flux for two years during operation at the nuclear power plant Gösgen (Switzerland) (Wieland et al., 2017). The thickness of the oxide layer of the irradiated steel samples was not determined experimentally prior to the corrosion experiment. However, based on ample evidence presented in the literature (e.g., Chimi et al., 2016; Hanbury and Was, 2019; Raiman and Was, 2017; Sakuragi et al., 2016; Was, 2017; Zhao et al., 2021), it is safe to assume that a few tenths to few hundred nanometer thick oxide layer had formed during irradiation in the nuclear reactor.

${ }^{14} \mathrm{C}$ is expected to be mainly produced by the activation of ${ }^{14} \mathrm{~N}$ impurities in the irradiated bulk metal matrix. It is conceivable that in the oxide layer the conversion of ${ }^{17} \mathrm{O}$ according to the nuclear reaction ${ }^{17} \mathrm{O}(\mathrm{n}, \alpha){ }^{14} \mathrm{C}$ was an additional source of ${ }^{14} \mathrm{C}$. However, the amount of ${ }^{14} \mathrm{C}$ resulting from ${ }^{17} \mathrm{O}$ conversion is expected to be much lower than the ${ }^{14} \mathrm{C}$ released during the corrosion of the bulk metal due to the much lower isotopic abundance of ${ }^{17} \mathrm{O}(0.038 \%)$ compared to ${ }^{14} \mathrm{~N}(99.632 \%)$ and the much lower thermal neutron cross section of ${ }^{17} \mathrm{O}(0.235)$ compared to ${ }^{14} \mathrm{~N}(1.82)$. The ${ }^{14} \mathrm{C}$ content of the irradiated steel nut was determined to be $17.8 \pm$ $2.1 \mathrm{kBq} / \mathrm{g}$ (corresponding to $0.107 \pm 0.012 \mu \mathrm{g}{ }^{14} \mathrm{C} / \mathrm{g}$ ) using a digestion procedure in oxidative media and ${ }^{14} \mathrm{C}$ quantification by liquid scintillation counting (LSC) (Schumann et al., 2014).

\subsection{Reactor}

The experimental set-up consists of a gas-tight overpressure reactor (stirred autoclave type "Versoclave Type 3", Büchi AG, Uster, Switzerland) surrounded by a 10-cm-thick lead shielding (Wieland et al., 2018; Wieland et al., 2017) (Supplementary Information (S.I.) Fig. S1-1). Before starting the corrosion experiment, tests of the background ${ }^{14} \mathrm{C}$ activity and the concentrations of carbon compounds were carried out (Cvetković et al., 2018c) (S.I. S2). For the experiment, two specimens of irradiated steel were mounted to a sample holder connected to a stirring device in the reactor. The reactor was tightly sealed and purged with $\mathrm{N}_{2}$ to ensure $\mathrm{O}_{2}$-free conditions. A volume of $300 \mathrm{~mL}$ ACW was injected via the in-house developed sampling system located outside the lead shielding (Cvetković et al., 2018c; Wieland et al., 2018; Wieland et al., 2017). After one day, the solution was replaced with a fresh one and the experiment started (Cvetković et al., 2018c). The ${ }^{14} \mathrm{C}$ background of the injected ACW solution was monitored over time (S.I. Table S2-1).

\subsection{Samplings}

Liquid and gas phase samples were collected on days 1, 14, 28, 92, 286, 412, 552, 1114, 1252, 1462 and 1637 (S.I. Table S3-1). Each time, approximately $7 \mathrm{~mL}$ solution and $50 \mathrm{~mL}$ gas were collected in separate sampling tubes as reported elsewhere (Cvetković et al., 2018c). After sampling, $7 \mathrm{~mL}$ of $\mathrm{O}_{2}$-free ACW and $\mathrm{N}_{2}$ were immediately injected into the reactor 
to maintain similar conditions throughout the experiment (i.e. $\sim 300 \mathrm{~mL}$ solution and $\sim 5$ bar pressure with $\mathrm{N}_{2}$ atmosphere). During sampling, pressure, temperature and dissolved $\mathrm{O}_{2}$ concentration were constantly monitored to verify gas-tightness of the reactor (Wieland et al., 2018; Wieland et al., 2017) (S.I. Table S3-1).

\subsection{Analytical methods}

\subsubsection{Total inorganic and organic ${ }^{14} \mathrm{C}$ contents of the liquid phase}

The total organic ${ }^{14} \mathrm{C}$ content $\left(\mathrm{TO}^{14} \mathrm{C}\right.$ ) was determined in three different ways: directly in the sampled solution (i.e. d-TO ${ }^{14} \mathrm{C}$ ); after pre-treatment of the solution with an $\mathrm{Ag} / \mathrm{Ba} / \mathrm{H}$ cartridge (OnGuard cartridges, Dionex, Sunnyvale, CA, USA) (i.e. $\mathrm{p}-\mathrm{TO}^{14} \mathrm{C}$ ), and as the sum of the concentrations of all organic ${ }^{14} \mathrm{C}$-bearing carbon compounds identified and quantified. The total inorganic ${ }^{14} \mathrm{C}$ content $\left(\mathrm{TI}^{14} \mathrm{C}\right)$, $\mathrm{p}$ - and $\mathrm{d}-\mathrm{TO}^{14} \mathrm{C}$ were determined by wet oxidation (WO) as described elsewhere (Guillemot et al., 2021; Rauber, 2018). Briefly, $3 \times 1.25 \mathrm{~mL}$ (on sampling day 1114) or $3 \times 0.125 \mathrm{~mL}$ (starting from sampling day 1252) of the alkaline solutions collected from the reactor were pipetted into pre-cleaned EXETAINER ${ }^{\circledR}$ vials $(12 \mathrm{~mL}$, screw cap, item 938 W, Labco Limited, Lampeter, UK) in triplicate inside a glovebox $\left(\mathrm{O}_{2}\right.$ and $\left.\mathrm{CO}_{2}<0.1 \mathrm{ppm}\right)$ (Guillemot et al., 2021; Rauber, 2018). The volume of the sample solution was adjusted that samples could be prepared that allowed ${ }^{14} \mathrm{C}$ measurements in the optimal dynamic range of the AMS. The solutions were spiked with aliquots of ${ }^{14} \mathrm{C}$-free $\mathrm{KH}^{12 /}$ ${ }^{13} \mathrm{CO}_{3}$ and ${ }^{12 / 13} \mathrm{C}$-acetate carriers to provide $\sim 50 \mu \mathrm{g}$ stable carbon. Three blanks were prepared by mixing 1.25 or $0.125 \mathrm{~mL}$ ACW, respectively, with the ${ }^{14} \mathrm{C}$-free carriers. All vials were tightly sealed, frozen and analyzed by WO combined with ${ }^{14} \mathrm{C}$ quantification by AMS at the Laboratory for Analysis of Radiocarbon (LARA; University of Bern, Switzerland), as detailed elsewhere (Rauber, 2018). For d-TO ${ }^{14} \mathrm{C}$ measurements, $250 \mu \mathrm{L}$ of oxidizing agent $\left(10 \% \mathrm{~K}_{2} \mathrm{~S}_{2} \mathrm{O}_{8}\right.$; Sigma-Aldrich, ACS reagent > 99\%) solution in $5 \% \mathrm{H}_{3} \mathrm{PO}_{4}$ (Merck $85 \%$ suprapur ${ }^{\circledR}$ ) was injected into the sample vials after the $\mathrm{TI}^{14} \mathrm{C}$ measurements. Within the two hours of reaction, $\mathrm{TO}^{14} \mathrm{C} / \mathrm{TOC}$ was converted to ${ }^{14} \mathrm{CO}_{2} / \mathrm{CO}_{2(\mathrm{~g})}$, which were transferred into the AMS via the gas interface system (GIS) (Rauber, 2018). The $\mathrm{p}-\mathrm{TO}^{14} \mathrm{C}$ was determined by spiking $800 \mu \mathrm{L}$ of the solution pre-treated with the $\mathrm{Ag} / \mathrm{Ba} / \mathrm{H}$ cartridge with $1.25 \mathrm{M}{ }^{14} \mathrm{C}$-free acetate carrier. Before sampling day $1114,10 \mu \mathrm{L}$ of the solution was combusted in an elemental analyzer (EA) (Elementar, Langenselbold, Germany) and ${ }^{14} \mathrm{CO}_{2} / \mathrm{CO}_{2}$ injected into the AMS via the GIS (Cvetković et al., 2018c; Salazar et al., 2015). Starting with sampling day 1114 , $\mathrm{p}-\mathrm{TO}^{14} \mathrm{C}$ was determined by WO, as this technique allows injection of ${ }^{14} \mathrm{CO}_{2}$ from $5 \mathrm{~mL}$ solution.

\subsubsection{Aqueous ${ }^{14} \mathrm{C}$-bearing carbon compounds}

Dissolved carbon compounds were separated and identified by high performance ion exchange chromatography (HPIEC) using an ICS-5000 ion chromatography (IC) in combination with a mass spectrometer (MS) system (Dionex/Thermo Fisher, Sunnyvale, CA, USA). Chromeleon 7 software (SR 11d) was used for IC data acquisition and processing, while Xcalibur Finnigan Surveyor MSQ 1.1 ELMO software controlled the MS, as reported elsewhere (Cvetković et al., 2018a; Cvetković et al., 2018b; Guillemot et al., 2020a). To an $800 \mu \mathrm{L}$ aliquot of solution previously pretreated by the $\mathrm{Ag} / \mathrm{Ba} / \mathrm{H}$ cartridge, $2 \mu \mathrm{L}$ of a $6 \mathrm{mM}^{14} \mathrm{C}$-free acetate carrier were added. Pre-treatment with the cartridge removed interfering anions (e.g. $\mathrm{Cl}^{-}$) from solution and reduced the $\mathrm{pH}$ to $\sim 6$, which improved peak resolution. The mixture of solution and stable carbon carrier was injected into the IC via an injection loop $(14 \mu \mathrm{L})$ and eluted at a flow rate of $0.25 \mathrm{~mL} / \mathrm{min}$ using a $250 \mathrm{~mm} \times 2 \mathrm{~mm}$ i.d. IonPac AS11-HC column, $\mathrm{KOH}$ as mobile phase, and an elution program described elsewhere (Cvetković et al., 2018b; Cvetković et al., 2018c; Guillemot et al., 2021).

Formic acid (FA), acetic acid (AA), lactic acid (LA), malonic acid (MA) and oxalic acid (OA) were the main dissolved stable carbon organics identified by HPIEC and separated according to their retention times using a fraction collector (Foxy Jr. ${ }^{\circledR}$ Fraction collector, Teledyne Isco, Lincoln, NE, USA) (Cvetković et al., 2018a; Cvetković et al., 2018b). The pretreated solution was injected nine times consecutively and the nine fractions of each individual carboxylic acid (CA) were collected in a single vial (total volume of $\sim 500 \mu \mathrm{L}$ ). The sample was further diluted to $5 \mathrm{~mL}$ and analyzed by WO combined with ${ }^{14} \mathrm{C}$ quantification by AMS.

\subsubsection{Total gaseous ${ }^{14} \mathrm{C}$ content}

The gas chromatographic (GC) system used for identification and sample preparation consists of a TRACE ${ }^{\mathrm{TM}} \mathrm{GC}$ (Thermo Fisher Scientific Inc., Waltham, USA, operated with the Thermo Xcalibur 3.0.63 software), an oxidation reactor (Thermo Finnigan, Bremen, Germany), and a custom-built fraction collector operated by a custom-built software (Brechbühler AG, Schlieren, Switzerland). The GC setup as well as the methods developed to determine the total ${ }^{14} \mathrm{C}$ content in the gas phase $\left(\mathrm{TG}^{14} \mathrm{C}\right)$ have been described in detail elsewhere (Guillemot et al., 2021; Guillemot et al., 2020b). Briefly, an aliquot of the gas collected from the reactor (i.e. $40 \mu \mathrm{L}$ on day $1114 ; 500 \mu \mathrm{L}$ thereafter) was loaded into the sample loop of the GC using a gas-tight syringe (Hamilton AG, Bonaduz, Switzerland). Also in this case, the volume of the sampled gas was adjusted to allow sample preparation for the optimal dynamic range of the AMS. ${ }^{14} \mathrm{C}$-free (fossil) $\mathrm{CH}_{4}$ (grade 5.0; Carbagas, AG, Liebefeld, Switzerland) was injected as a stable carbon carrier via the carrier loop of the GC to achieve $50 \mu \mathrm{g}$ of stable carbon. The sample and carrier were injected simultaneously and passed with the He flow through a fused silica capillary $(1 \mathrm{~m} \times 0.32 \mathrm{~mm})$ to the oxidation reactor, which was operated at $1000{ }^{\circ} \mathrm{C}$ to convert carbon compounds into $\mathrm{CO}_{2}$. Afterwards, the analyte stream sequentially passed through additional devices (a reduction oven to remove traces of $\mathrm{O}_{2}$ and nitrous oxides $\left(\mathrm{NO}_{\mathrm{x}}\right)$ and a water trap to remove residual water) before finally being collected in the fraction collector (Guillemot et al., 2021; Guillemot et al., 2020b). The fraction collector was transferred to LARA and connected to the GIS through a $1 \mathrm{~m}$ long 1/16" O.D. tubing. A He flow of $\sim 30 \mathrm{~mL} / \mathrm{min}$ was applied for $150-300$ s to purge the mixture of ${ }^{14} \mathrm{CO}_{2} / \mathrm{CO}_{2}$ from the sampling loops into the GIS zeolite trap, which was heated up to release the ${ }^{14} \mathrm{CO}_{2}$ / $\mathrm{CO}_{2}$ mixture into the AMS gas ion source for ${ }^{14} \mathrm{C}$ quantification (Salazar et al., 2015; Wacker et al., 2013).

\subsubsection{Gaseous ${ }^{14} \mathrm{C}$-bearing carbon compounds}

The GC system previously described was also used to separate the individual ${ }^{14} \mathrm{C}$-bearing carbon compounds. The setup and development of the method have been described in detail elsewhere (Guillemot et al., 2021; Guillemot et al., 2020b). Briefly, $500 \mu \mathrm{L}$ of gas sample was injected through the sample loop simultaneously with a defined amount of ${ }^{14} \mathrm{C}$-free (fossil) carrier through a second (carrier) loop. Previous studies reported $\mathrm{CH}_{4}$, $\mathrm{CO}, \mathrm{C}_{2} \mathrm{H}_{6}$ and $\mathrm{C}_{3} \mathrm{H}_{8}$ as the main gaseous carbon compounds produced during the corrosion of iron and steel (Cvetković et al., 2018a; de VisserTýnová et al., 2018; Guillemot et al., 2020a; Wieland and Hummel, 2015) and therefore these compounds were added as ${ }^{14} \mathrm{C}$-free carriers. The compounds were separated using a Restek Rt ${ }^{\circledR}-$ Msieve $5 \mathrm{~A}$ column ( $30 \mathrm{~m} \times 0.32 \mathrm{~mm}$ with $0.025 \mathrm{~mm}$ film) and a temperature program previously reported (Guillemot et al., 2021; Guillemot et al., 2020b). The separated compounds were oxidized in the oxidation reactor $\left(1000{ }^{\circ} \mathrm{C}\right)$ to ${ }^{14} \mathrm{CO}_{2} / \mathrm{CO}_{2}$ and eventually collected in the sampling loops of the fraction collector. Injection into the AMS via the GIS was performed as previously described for $\mathrm{TG}^{14} \mathrm{C}$ analysis.

\subsubsection{Hydrogen}

The $\mathrm{H}_{2}$ concentration in the gas phase was determined using GC-MS as it is an indicator of the anoxic corrosion of steel (Jelinek and Neufeld, 1982) (Eq. (1)). $10 \mathrm{~mL}$ of the gas volume collected from the reactor were withdrawn from the sampling tube using a gas-tight syringe and injected into a purged and evacuated $20 \mathrm{~mL}$ vial. To equalize pressure, each vial was then connected to a gas bag filled with $\mathrm{N}_{2}$ (grade 5.0, Carbagas AG, Liebefeld, Switzerland) for five seconds. The Restek Rt $($-Msieve 5A GC column $(30 \mathrm{~m} \times 0.32 \mathrm{~mm}$ with $0.025 \mathrm{~mm}$ film) was used in combination with the following temperature program: initial temperature of $45^{\circ} \mathrm{C}$ (isothermal for $4 \mathrm{~min}$ ), heating at a rate of $20{ }^{\circ} \mathrm{C} / \mathrm{min}$ to $290{ }^{\circ} \mathrm{C}$ (isothermal for $10 \mathrm{~min}$ ), resulting in a total run time of $\sim 26 \mathrm{~min}$. Hydrogen $\left(\mathrm{H}_{2}\right)$ was 
detected by MS in selected ion monitoring (SIM) mode with standard EI parameters (i.e. $70 \mathrm{eV}$ collision energy and $230{ }^{\circ} \mathrm{C}$ MS source temperature) and appeared in the chromatogram with the specific mass fragment 5 generated by protonation of the carrier gas $(\mathrm{He})$ with by $\mathrm{H}^{+}$, as described elsewhere (Varlet et al., 2013). Standards were prepared in $20 \mathrm{~mL}$ vials in the dynamic range between 0 and $8 \mu \mathrm{H} \mathrm{H}_{2} / \mathrm{mL}$ gas volume using pure $\mathrm{H}_{2}$ (Messer Schweiz AG, Lenzburg, Switzerland) diluted with $\mathrm{N}_{2}$ after pressure equalization. It should be noted that the scatter in the $\mathrm{H}_{2}$ measurements was quite large, which is due to the possibility of different losses of small amounts of gas during the GC-MS measurements.

\subsection{Accelerator mass spectrometry}

Quantifications of $\mathrm{TI}^{14} \mathrm{C}, \mathrm{d}-\mathrm{TO}^{14} \mathrm{C}$, $\mathrm{p}-\mathrm{TO}^{14} \mathrm{C}$, individual ${ }^{14} \mathrm{C}$-bearing $\mathrm{CAs}, \mathrm{TG}^{14} \mathrm{C}$ and individual ${ }^{14} \mathrm{C}$-bearing gaseous carbon compounds were performed at LARA using a $200 \mathrm{kV}$ MIni CArbon DAting System (MICADAS) (Szidat et al., 2014). The standards used were $5 \% \mathrm{CO}_{2}$ from oxalic acid II from National Institute of Standards and Technology (SRM 4990C) in helium prepared by Hekal AMS Lab (Hungary) and 4.5\% fossil $\mathrm{CO}_{2}$ in $\mathrm{He}$ from Messer AG (Switzerland). The linear dynamic range of the ${ }^{14} \mathrm{C}$ measurements was found to span three orders of magnitude between $0.06 \mathrm{~F}^{14} \mathrm{C}-50 \mathrm{~F}^{14} \mathrm{C}$ (fraction modern carbon), corresponding to a concentration range from 0.01 to $9.8 \mathrm{pmol}{ }^{14} \mathrm{C} / \mathrm{L}$ in solution (Cvetković et al., 2018b). The MICADAS and associated equipment (i.e. GIS, EA etc.) were controlled and accessed by Transmission Control Protocol/Internet Protocol commands generated by LabView (Salazar et al., 2015; Szidat et al., 2014; Wacker et al., 2013).

\subsection{Data treatment}

Results from the ${ }^{14} \mathrm{C}$ AMS measurements were expressed in terms of $\mathrm{F}^{14} \mathrm{C}$. For the liquid samples, the $\mathrm{F}^{14} \mathrm{C}$ values were converted to molar ${ }^{14} \mathrm{C}$ concentrations (M) and volume-related ${ }^{14} \mathrm{C}$ activities $(\mathrm{Bq} / \mathrm{L})$, taking into account several parameters related to the analytical procedure used, such as the amount of stable carbon carrier added (i.e. $20-50 \mu \mathrm{g}{ }^{12 / 13} \mathrm{C}$ ) and the volume of solution used for ${ }^{14} \mathrm{CO}_{2} / \mathrm{CO}_{2}$ injection into the AMS source (S.I. S4). For the gas samples, $\mathrm{F}^{14} \mathrm{C}$ values were converted to ${ }^{14} \mathrm{C}$ concentrations (mol/L gas volume) and volume-related ${ }^{14} \mathrm{C}$ activities $(\mathrm{Bq} / \mathrm{L}$ ) based on the gas volume normalized to ambient temperature $\left(22^{\circ} \mathrm{C}\right)$ and pressure ( 1 bar) by taking into account the parameters related to the analytical procedure used, such as the amount of stable carbon carrier added and the volume of gas sample injected (S.I. S4). The evolution of the ${ }^{14} \mathrm{C}$ concentrations in the reactor was quantified by correcting with the dilution factors of both aqueous and gas phases at each sampling due to the replacement of $7 \mathrm{~mL}$ sampled solution by ACW and the sampled gas by $\mathrm{N}_{2}$. The dilution factors were calculated based on the weighted amount of solution sampled, the weighted amount of fresh ACW injected and the different pressure readings at each sampling step (S.I. Table S4-1).

\section{Results}

In this corrosion experiment with irradiated steel, ${ }^{14} \mathrm{C}$ concentrations were in the pico- to femtomolar range (S.I. Table S5-1, S5-3, and S5-5), as expected, due to the small size and low ${ }^{14} \mathrm{C}$ content of the two irradiated steel samples, the very slow corrosion of stainless steel in alkaline solution, and finally the small volume of solution and gas collected from the reactor and used for the ${ }^{14} \mathrm{C}$ analyses. The AMS-based analytical techniques allowed us to quantify ${ }^{14} \mathrm{C}$ in the ultra-trace range, but a relatively large statistical uncertainty (up to $30 \%$ ) had to be accepted for the liquid samples due to limited repeatability of the measurements.

The ${ }^{14} \mathrm{C}$ concentrations determined over time in the liquid and gas phases of the reactor were corrected with the corresponding dilution factors and normalized to the total surface area of the two steel samples (i.e., $11.15 \mathrm{~cm}^{2}$ ) in order to account for surface-related ${ }^{14} \mathrm{C}$ release (Fig. 1) (S.I. Table S5-2, S5-4, and S5-6). The ${ }^{14} \mathrm{C}$ content determined after pre-treatment of the solution with the OnGuard cartridge $\left(\mathrm{p}-\mathrm{TO}^{14} \mathrm{C}\right)$ was quantified from the beginning of the experiment (Fig. 1a). The other parameters were quantified on sampling day 1114 and thereafter, after the WO method was introduced (Guillemot et al., 2021) (Fig. 1 b-d).

Fig. 1a shows that $\mathrm{p}-\mathrm{TO}^{14} \mathrm{C}$ increased sharply within the first $\sim 30$ days after immersion of the two samples in ACW, i.e. $\mathrm{p}-\mathrm{TO}^{14} \mathrm{C}$ increased from $1.2 \times 10^{-14} \mathrm{M}$ to $6.4 \times 10^{-13} \mathrm{M}$ (S.I. Table S5-2) (Fig. 1a). Direct measurements of $\mathrm{TO}^{14} \mathrm{C}$ (i.e. d-TO ${ }^{14} \mathrm{C}$ ) from sampling day 1114 and thereafter confirmed that after the initial phase, both $\mathrm{p}$ - and $\mathrm{d}-\mathrm{TO}^{14} \mathrm{C}$ were constant during the course of steel corrosion (Fig. 1a). The d-TO ${ }^{14} \mathrm{C}$ varied between $8.3 \pm 1.1 \times 10^{-13} \mathrm{M}$ and $9.8 \pm 3.5 \times 10^{-13} \mathrm{M}$ (S.I. Table S5-2). $\mathrm{TI}^{14} \mathrm{C}$ was also nearly constant with time (Fig. 1b), varying between $3.0 \pm$ $1.0 \times 10^{-13} \mathrm{M}$ and $3.6 \pm 1.3 \times 10^{-13} \mathrm{M}$ (S.I. Table S5-2). In contrast to $\mathrm{p}-\mathrm{TO}^{14} \mathrm{C}$, $\mathrm{d}-\mathrm{TO}^{14} \mathrm{C}$ and $\mathrm{TI}^{14} \mathrm{C}$, the ${ }^{14} \mathrm{C}$ content in the gas phase $\left(\mathrm{TG}^{14} \mathrm{C}\right)$ increased slowly but steadily with time over the 1.5-year gas sampling period from $2.6 \pm 0.1 \times 10^{-13} \mathrm{M}$ to $4.2 \pm 0.1 \times 10^{-13} \mathrm{M}$ (Fig. 1c) (S.I. Table S5-6).

The corrosion of stainless steel under anoxic conditions can be described as follows (Jelinek and Neufeld, 1982):

$3 \mathrm{Fe}+4 \mathrm{H}_{2} \mathrm{O} \rightarrow \mathrm{Fe}_{3} \mathrm{O}_{4}+4 \mathrm{H}_{2}$

The time-dependent increase in $\mathrm{H}_{2}$ concentration is thus a direct measure of the anoxic corrosion of steel and was determined on sampling day 1114 and thereafter (S.I. Table S5-7). Fig. 1d compares the surfacenormalized $\mathrm{H}_{2}$ release according to Eq. (1) and predicted by Eq. (2) with the experimental data. In addition to $\mathrm{H}_{2},{ }^{14} \mathrm{C}$ is an additional tracer associated with the steel corrosion in this study.

The following equation was used to relate the release of ${ }^{14} \mathrm{C}$ and $\mathrm{H}_{2}(\mathrm{~m}$ (t)) to the corrosion rate of stainless steel (Cvetković et al., 2018c):

$\mathrm{m}(\mathrm{t})=\int_{0}^{\mathrm{t}} \frac{\mathrm{R}_{\mathrm{c}} \mathrm{A} \rho \mathrm{v}}{\mathrm{M}_{\mathrm{w}}} \mathrm{dt}[\mathrm{mol}]$

$\mathrm{R}_{\mathrm{c}}$ : Corrosion rate $[\mathrm{m} / \mathrm{yr}]$;

A: Surface area of specimens in reactor $\left(\mathrm{A}=\mathrm{m}_{\mathrm{Fe}} \cdot \mathrm{S}_{\mathrm{m}}\right)\left[\mathrm{m}^{2}\right]$ with $\mathrm{m}_{\mathrm{Fe}}$ : Mass of the two specimens $\left(=1.718 \times 10^{-3} \mathrm{~kg}\right)$ and $\mathrm{S}_{\mathrm{m}}$ : Specific surface area $\left(=0.649 \mathrm{~m}^{2} / \mathrm{kg}\right)$;

$\mathrm{M}_{\mathrm{w}}$ : Molecular weight of iron $(0.055845 \mathrm{~kg} / \mathrm{mol})$;

$\rho$ : Density of iron $\left(7855 \mathrm{~kg} / \mathrm{m}^{3}\right)$;

v: Stoichiometric factors: ${ }^{14} \mathrm{C}\left(=4.27 \times 10^{-7}\right)$ expressed in terms of mol ${ }^{14} \mathrm{C} / \mathrm{mol} \mathrm{Fe}$ of irradiated steel; $\mathrm{H}_{2}(4 / 3)$ according to Eq. (1).

The ${ }^{14} \mathrm{C}$ release into solution and gas phase (normalized to the surface area of the specimens) was modeled for corrosion rates between $1 \mathrm{~nm} / \mathrm{yr}$ and up to $100 \mathrm{~nm} / \mathrm{yr}$. These values are within the range of rates reported for stainless steel corrosion in alkaline solution (Diomidis, 2014; Smart, 2009; Swanton et al., 2015). For modeling purposes, a constant ${ }^{14} \mathrm{C}$ inventory of irradiated steel was assumed, which is supported by mass balance calculations. These show that less than $0.01 \%$ of the ${ }^{14} \mathrm{C}$ inventory of stainless steel was released into the solution and the gas phase during more than four years of corrosion. The calculations further assume that ${ }^{14} \mathrm{C}$ released from irradiated steel is converted to either gaseous or aqueous species. For consistency, the modeling was based on the assumption of an initial rapid release of ${ }^{14} \mathrm{C}$ at a rate of $20 \mathrm{~nm} / \mathrm{yr}$ for all parameters, as indicated by the increase in $\mathrm{p}-\mathrm{TO}^{14} \mathrm{C}$ within the first 30 days of corrosion. This indicates the presence of surface sites on steel with higher reactivity in the case of the gaseous species.

A comparison of the distribution of the ${ }^{14} \mathrm{C}$ contents between the liquid $\left(\mathrm{TI}^{14} \mathrm{C}, \mathrm{TO}^{14} \mathrm{C}\right)$ and gas phase $\left(\mathrm{TG}^{14} \mathrm{C}\right)$ fractions demonstrates the timedependent increase in $\mathrm{TG}^{14} \mathrm{C}$ from $42 \pm 12 \%$ on day 1114 to $53 \pm 16 \%$ on day 1637 as a result of the corrosion process (Fig. 2). In contrast, $\mathrm{TO}^{14} \mathrm{C}$ and $\mathrm{TI}^{14} \mathrm{C}$ remained constant, which means that their relative share decreases with time (Fig. 2). 

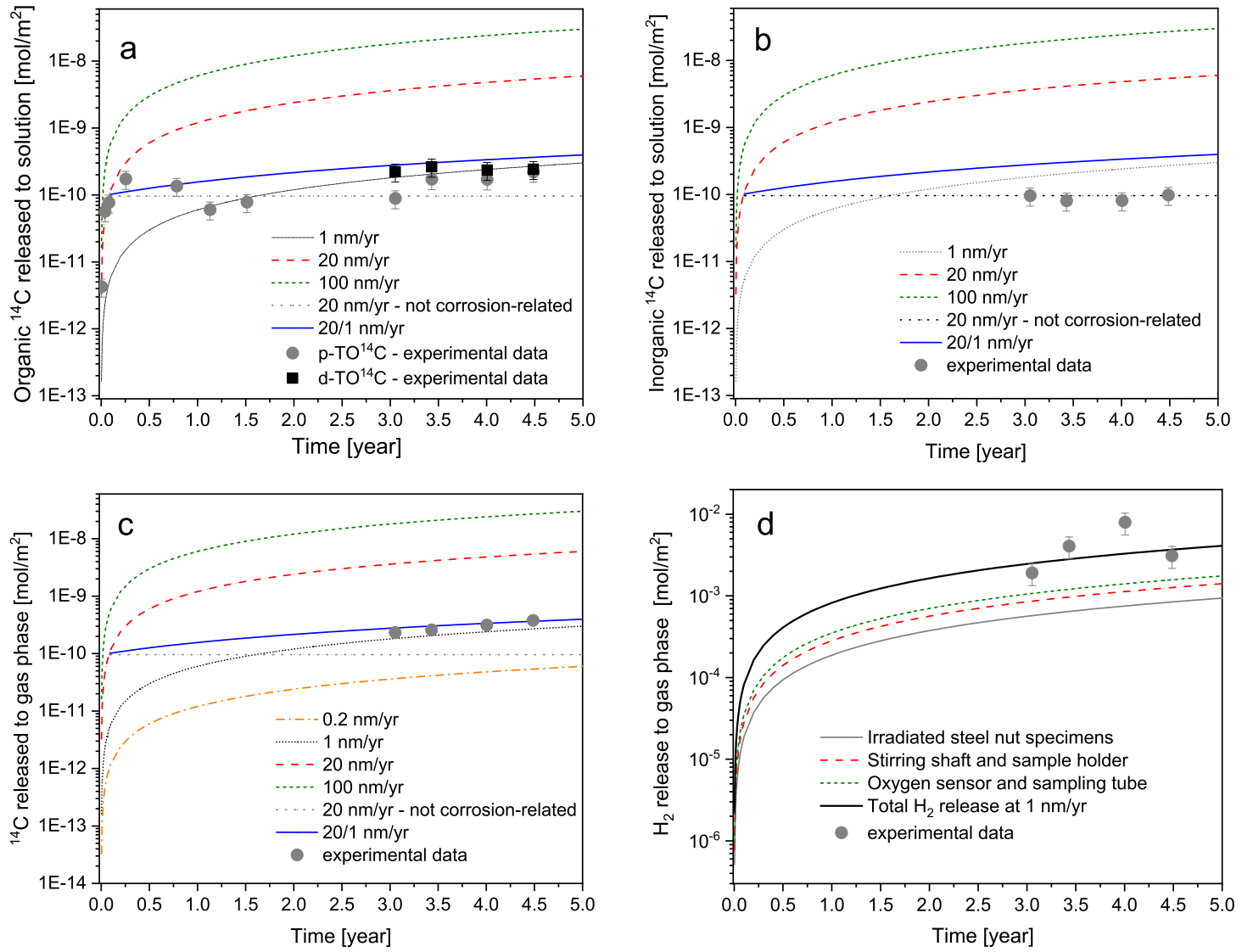

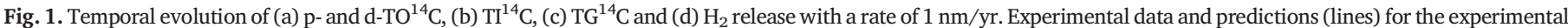

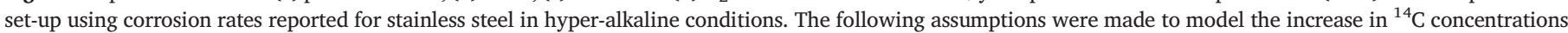

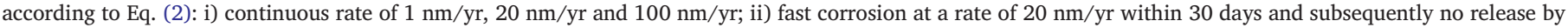
corrosion; iii) fast corrosion at a rate of $20 \mathrm{~nm} / \mathrm{yr}$ within 30 days and subsequent slow corrosion at a rate of $1 \mathrm{~nm} / \mathrm{yr}(20 / 1 \mathrm{~nm} / \mathrm{yr}$ ).

The AMS-based CSRA was developed to identify and quantify the individual ${ }^{14} \mathrm{C}$-bearing carbon species in solution, such as ${ }^{14} \mathrm{C}$-FA, ${ }^{14} \mathrm{C}$-AA, ${ }^{14} \mathrm{C}$ OA, ${ }^{14} \mathrm{C}$-MA, and ${ }^{14} \mathrm{C}$-LA, as well as ${ }^{14} \mathrm{C}$-HCs (i.e. ${ }^{14} \mathrm{CH}_{4},{ }^{14} \mathrm{C}_{2} \mathrm{H}_{6},{ }^{14} \mathrm{C}_{3} \mathrm{H}_{8}$ ) and ${ }^{14} \mathrm{CO}$ in the gas phase.

The concentrations of ${ }^{14} \mathrm{C}$-FA, ${ }^{14} \mathrm{C}$-AA, ${ }^{14} \mathrm{C}$-OA, ${ }^{14} \mathrm{C}$-MA, and ${ }^{14} \mathrm{C}$-LA were determined on sampling days 1252, 1462 and 1637 (S.I. Tables S5-3 and 5-4). The total concentration of the ${ }^{14} \mathrm{C}$-bearing CAs was calculated by assuming that each CA carries only one ${ }^{14} \mathrm{C}$ atom (S.I. Table S5-4). The concentrations were averaged since no trend was discernible in the data. The average concentrations of the individual ${ }^{14} \mathrm{C}$-bearing CAs were as follows:
${ }^{14} \mathrm{C}-\mathrm{FA}=7.4 \pm 1.1 \times 10^{-14} \mathrm{M},{ }^{14} \mathrm{C}-\mathrm{AA}=11.1 \pm 1.2 \times 10^{-14} \mathrm{M},{ }^{14} \mathrm{C}-$ $\mathrm{OA}=9.0 \pm 3.4 \times 10^{-14} \mathrm{M},{ }^{14} \mathrm{C}-\mathrm{MA}=5.3 \pm 2.6 \times 10^{-14} \mathrm{M}$, and ${ }^{14} \mathrm{C}-$ $\mathrm{LA}=6.3 \pm 1.4 \times 10^{-14} \mathrm{M}$. Fig. 3a shows their contribution to the d$\mathrm{TO}^{14} \mathrm{C}$. It was estimated that the total concentration of the ${ }^{14} \mathrm{C}$-bearing CAs corresponds to $42 \pm 19 \%$ and $58 \pm 10 \%$ of the $\mathrm{d}-\mathrm{TO}^{14} \mathrm{C}$ and $\mathrm{p}$ $\mathrm{TO}^{14} \mathrm{C}$, respectively.

The individual gaseous ${ }^{14} \mathrm{C}$-bearing compounds have been identified and quantified since sampling day 1114 (S.I. Tables S5-5 and 5-6). ${ }^{14} \mathrm{CH}_{4}$ proved to be the most important ${ }^{14} \mathrm{C}$-bearing $\mathrm{HC}$ (Fig. 3b). Its concentration increased from $2.6 \pm 0.1 \times 10^{-13} \mathrm{M}$ to $3.5 \pm 0.2 \times 10^{-13} \mathrm{M}$ between

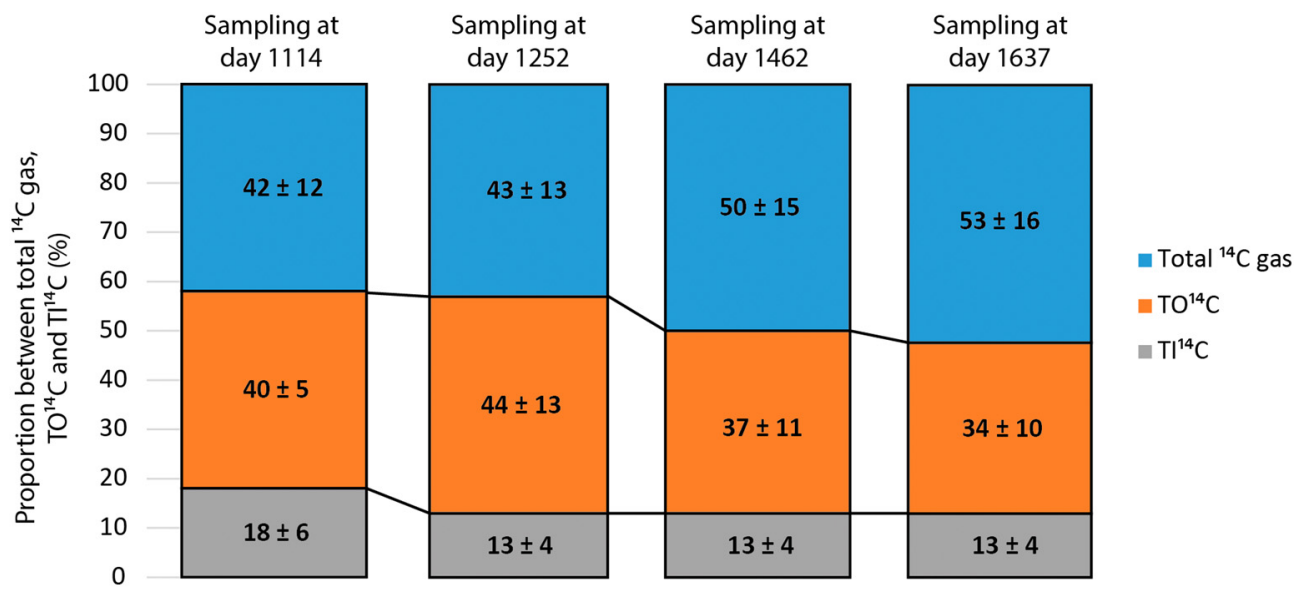

Fig. 2. Distribution of the ${ }^{14} \mathrm{C}$-bearing compounds in the liquid and gas phases between three and four years of alkaline anoxic corrosion of irradiated steel. 

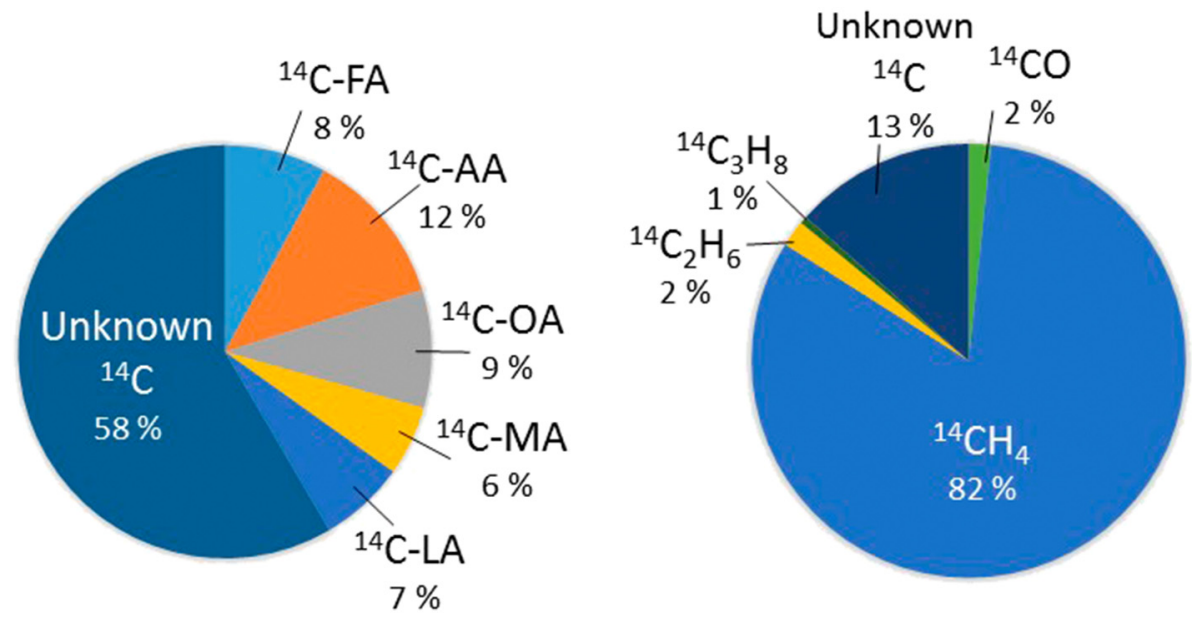

Fig. 3. Proportions of (a) ${ }^{14} \mathrm{C}$-bearing $\mathrm{CAs}$ to the $\mathrm{d}-\mathrm{TO}^{14} \mathrm{C}$ (average from sampling day 1252 to 1637 ) and (b) ${ }^{14} \mathrm{C}$-bearing gaseous compounds to the $\mathrm{TG}{ }^{14} \mathrm{C}$ on sampling day 1637.

sampling day 1114 and 1637 (S.I. Table S5-6). Additionally, other small ${ }^{14} \mathrm{C}$-bearing $\mathrm{HCs}$ and ${ }^{14} \mathrm{CO}$ were quantified to estimate their contribution to $\mathrm{TG}^{14} \mathrm{C}$ (Fig. 3b). ${ }^{14} \mathrm{C}_{2} \mathrm{H}_{6}$ showed a slight increase in concentration between sampling day 1252 and 1637 from $5.9 \pm 0.1 \times 10^{-15} \mathrm{M}$ to $8.2 \pm 2.1 \times 10^{-15} \mathrm{M} .{ }^{14} \mathrm{C}_{3} \mathrm{H}_{8}$ and ${ }^{14} \mathrm{CO}$ were quantified only on sampling day $1637\left(2.3 \pm 0.9 \times 10^{-15} \mathrm{M}\right.$ and $7.0 \pm 2.1 \times 10^{-15} \mathrm{M}$, respectively). It should be noted that the concentrations of ${ }^{14} \mathrm{C}_{2} \mathrm{H}_{6},{ }^{14} \mathrm{C}_{3} \mathrm{H}_{8}$ and ${ }^{14} \mathrm{CO}$ were close to the limit of quantification (LOQ).

\section{Discussion}

\subsection{Time-dependent release of ${ }^{14} \mathrm{C}$}

The evolution of $\mathrm{TI}^{14} \mathrm{C}$, $\mathrm{p}$ - and $\mathrm{d}-\mathrm{TO}^{14} \mathrm{C}$ in solution and $\mathrm{TG}^{14} \mathrm{C}$ in the gas phase is related to the release from irradiated steel, since no other ${ }^{14} \mathrm{C}$ source was identified in the reactor. In addition, replacing an aliquot of the solution in the reactor with ACW only slightly increased the background ${ }^{14} \mathrm{C}$ content (S.I. Table S2-1).

The model predictions show that $\mathrm{p}-\mathrm{TO}^{14} \mathrm{C}, \mathrm{d}-\mathrm{TO}^{14} \mathrm{C}$ and $\mathrm{TI}^{14}$ are not related to the long-term corrosion of irradiated steel, unlike $\mathrm{TG}^{14} \mathrm{C}$. The ${ }^{14} \mathrm{C}$ concentration in solution $\left(\mathrm{TO}^{14} \mathrm{C}, \mathrm{TI}^{14} \mathrm{C}\right.$ ) is considered to be the result of a rapid release of ${ }^{14} \mathrm{C}$ in the initial phase of the corrosion process. The long-term increase in $\mathrm{TG}^{14} \mathrm{C}$, however, occurs in accordance with a corrosion rate of stainless steel of $1 \mathrm{~nm} / \mathrm{yr}$. This value agrees very well with rates reported in other work for the corrosion of stainless steel in anoxic alkaline conditions (e.g., Diomidis, 2014; Senior et al., 2021; Smart, 2009; Swanton et al., 2015).

Quantification of $\mathrm{TO}^{14} \mathrm{C}$ and $\mathrm{TI}^{14} \mathrm{C}$ in solution and $\mathrm{TG}^{14} \mathrm{C}$ in the gas phase allowed us to establish a mass balance for ${ }^{14} \mathrm{C}$ during alkaline anoxic corrosion of irradiated steel. By knowing the ${ }^{14} \mathrm{C}$ inventory of the irradiated steel (i.e. $1.31 \times 10^{-8} \mathrm{~mol} / \mathrm{g}$; Schumann et al., 2014), it was possible to determine the fraction of ${ }^{14} \mathrm{C}$ released since the beginning of the corrosion experiment. By day 1637 of alkaline anoxic corrosion, $\sim 8.0 \times 10^{-13} \mathrm{~mol}^{14} \mathrm{C}$ had been released into the liquid and gas phases, corresponding to $\sim 0.0061 \%$ of the initial ${ }^{14} \mathrm{C}$ inventory of the irradiated steel samples.

The question arose whether the release of ${ }^{14} \mathrm{C}$ occurs in stoichiometric proportion to $\mathrm{H}_{2}$ production during corrosion. The modeling shows that the $\mathrm{H}_{2}$ concentration in the gas phase also increased according to a corrosion rate of $1 \mathrm{~nm} / \mathrm{yr}$ (Fig. 1d). However, it must be taken into account that in addition to the irradiated stainless steel specimens, the assembly parts of the reactor systems, such as parts of the stirring shaft with the sample holder, parts of the sampling tube and the oxygen sensor, were also exposed to alkaline solution (S.I. Fig. S1-1). The slow corrosion of these assembly parts made of stainless steel contributed to the $\mathrm{H}_{2}$ production. It should be noted that the assembly parts were not designed in a way to cause no $\mathrm{H}_{2}$ production because the corrosion experiment was primarily focused on the ${ }^{14} \mathrm{C}$ speciation during steel corrosion under alkaline anoxic conditions. In addition, the type of stainless steel used to make the assembly parts was not known, which led us to assume that the irradiated steel nuts and the assembly parts were made of the same stainless steel. The surface areas of the assembly parts are known (stirring shaft with sample holder: $16.75 \mathrm{~cm}^{2}$, dissolved oxygen sensor and sampling tube: $20.84 \mathrm{~cm}^{2}$ ), so the contribution of corrosion of these parts to the $\mathrm{H}_{2}$ production could be calculated and separated from $\mathrm{H}_{2}$ release by the irradiated steel samples (surface area: $11.15 \mathrm{~cm}^{2}$ ). The corrosion of the latter samples contributed about $22 \%$ to the total $\mathrm{H}_{2}$ production at a corrosion rate of $1 \mathrm{~nm} / \mathrm{yr}$. The results show that the release rate of ${ }^{14} \mathrm{C}$ from the irradiated stainless steel samples is identical to the corrosion rate of the material (stoichiometric release).

\subsection{Speciation}

Literature reviews and corrosion studies with irradiated steel and nonirradiated iron indicate the formation of low molecular weight (LMW) organic carbon compounds, such as CAs, as well as carbonate and hydrocarbons (HCs) during iron/steel corrosion (Cvetković et al., 2018a; de VisserTýnová et al., 2018; Guillemot et al., 2020a; Swanton et al., 2015; Wieland and Hummel, 2015).

The result show that dissolved organic carbon compounds account for $\mathrm{d}$ - and $\mathrm{p}-\mathrm{TO}^{14} \mathrm{C}$. The two parameters agree quite well, as $\mathrm{p}-\mathrm{TO}^{14} \mathrm{C}$ corresponds to $67 \pm 27 \%$ of the $\mathrm{d}-\mathrm{TO}^{14} \mathrm{C}$ on average. However, some of the ${ }^{14} \mathrm{C}$ contributing to the $\mathrm{TO}^{14} \mathrm{C}$ was retained by the $\mathrm{Ag} / \mathrm{Ba} / \mathrm{H}$ cartridge, presumably as colloidal ${ }^{14} \mathrm{C}$ or ${ }^{14} \mathrm{C}$ associated with larger organic molecules retained during filtration, which explains the difference between $\mathrm{d}-\mathrm{TO}^{14} \mathrm{C}$ and $\mathrm{p}-\mathrm{TO}^{14} \mathrm{C}$. In view of these results, the CAs can be considered as important organic ${ }^{14} \mathrm{C}$-carrying carbon compounds present in solution $(\sim 42 \%$ of the organic ${ }^{14} \mathrm{C}$ content in solution) during alkaline anoxic corrosion of irradiated steel (Fig. 3a). $\mathrm{TI}^{14} \mathrm{C}$ is attributed to the presence of ${ }^{14} \mathrm{CO}_{3}^{2-}$ under the given high-pH conditions. $\mathrm{TI}^{14} \mathrm{C}$ is about a factor of 3 lower than $\mathrm{d}-\mathrm{TO}^{14} \mathrm{C}$ (Fig. 2), suggesting that ${ }^{14} \mathrm{CO}_{3}^{2-}$ is not the predominant ${ }^{14} \mathrm{C}$-bearing species.

Previous studies have shown that oxidized carbon compounds, e.g. CAs, can be detected in solution under the anoxic conditions of iron-water systems (Cvetković et al., 2018a; Guillemot et al., 2020a; Wieland and Hummel, 2015 and references therein). Hence, the same oxygen-bearing carbon compounds have been observed in the current and previous corrosion studies (e.g., Swanton et al., 2015; Wieland and Hummel, 2015) (Table 1). In general, the formation of small CAs containing between one and five $\mathrm{C}$ atoms is observed (Wieland and Hummel, 2015, and references therein). It has been hypothesized that CAs are formed when iron/steel is 
Table 1

Stable carbon and ${ }^{14} \mathrm{C}$-bearing compounds identified during alkaline anoxic corrosion of non-activated iron powders and irradiated stainless steel.

\begin{tabular}{|c|c|c|c|}
\hline \multicolumn{2}{|c|}{ Corrosion of non-irradiated iron/steel ${ }^{\mathrm{a}}$} & \multicolumn{2}{|c|}{ Corrosion of irradiated steel ${ }^{\mathrm{b}}$} \\
\hline $\begin{array}{l}\text { Gaseous stable carbon } \\
\text { compounds }\end{array}$ & $\begin{array}{l}\text { Aqueous stable carbon } \\
\text { compounds }\end{array}$ & $\begin{array}{l}\text { Gaseous } \\
{ }^{14} \mathrm{C} \text {-compounds }\end{array}$ & $\begin{array}{l}\text { Aqueous } \\
{ }^{14} \mathrm{C} \text {-compounds }\end{array}$ \\
\hline Methane & Formate & Methane & Formate \\
\hline Ethane & Acetate & Ethane & Acetate \\
\hline Ethene & Propionate & Propane & Malonate \\
\hline Propane & Butanoate & Carbon monoxide & Oxalate \\
\hline Propene & Malonate & Carbon dioxide & Lactate \\
\hline Butane & Oxalate & & Carbonate \\
\hline Butylene $^{c}$ & Lactate & & \\
\hline Pentane $^{c}$ & Glycolate & & \\
\hline Pentene ${ }^{c}$ & Carbonate & & \\
\hline Hexane & Alcohols/aldehydes ${ }^{\mathrm{d}}$ & & \\
\hline
\end{tabular}

a See Swanton et al. (2015); Wieland and Hummel (2015) and references therein; Cvetković et al. (2018a); Guillemot et al. (2020a).

b See de Visser-Týnová et al. (2018); Kaneko et al. (2003); Yamashita et al. (2014); this study.

c Including isomers (e.g. trans-2-butene, cis-2-butene, 1-butene, iso-butene as well as 2-methylbutane, cis-2-pentene, trans-2-pentene).

d Including methanol, ethanol, propanol, formaldehyde, acetaldehyde, propionaldehyde.

exposed to oxic (humid) conditions and they are taken up by the oxide surface layer of the metal (Cvetković et al., 2018a; Guillemot et al., 2020a). Upon contact with a solution, the CAs are immediately released from the oxide layer by desorption. This hypothesis is further supported by the current study, as $\mathrm{p}-\mathrm{TO}^{14} \mathrm{C}$ increased rapidly in the initial phase of steel corrosion and remained constant thereafter (Fig. 1a). It is assumed that the release of organic and inorganic ${ }^{14} \mathrm{C}$ occurs by diffusion through the oxide layer and/or as a result of the conversion of iron oxyhydroxides into magnetite (Ishikawa et al., 1998; Tamaura et al., 1983). Nevertheless, we cannot exclude the possibility that the oxidized carbon species were alternatively produced in the reactor during the initial phase of the experiment due to the presence of small amounts of residual $\mathrm{O}_{2}$ in the solution.

Moreover, the irradiated stainless steel samples are the source of weak gamma radiation. The dose rate of $\mathrm{a} \sim 1 \mathrm{~g}$ specimen was estimated to be $\sim 0.12 \mathrm{~Gy} / \mathrm{h}$, based on the ${ }^{60} \mathrm{Co}$ and ${ }^{54} \mathrm{Mn}$ contents (Schumann et al., 2014). Depending on the dose rate, gamma radiation can produce different chemical species, in particular radicals (e.g. $\mathrm{HO} \cdot \mathrm{HO}_{2}{ }^{\circ}$ ) and peroxide $\left(\mathrm{H}_{2} \mathrm{O}_{2}\right)$ that act as oxidizing agents (Spinks and Woods, 1990). It should be noted that at the given very low dose rate of the irradiated steel samples, the concentration of $\mathrm{H}_{2} \mathrm{O}_{2}$ is expected to be far below the detection limit of standard analytical methods. However, the observed constant concentrations of ${ }^{14} \mathrm{C}$-bearing CAs, $\mathrm{TO}^{14} \mathrm{C}$ and $\mathrm{TI}^{14} \mathrm{C}$ indicate that ${ }^{14} \mathrm{C}$-CAs and ${ }^{14} \mathrm{C}$ bearing carbonate were not produced by radiation-induced radiolysis on the steel surface, since in this case a continuous increase in the above parameters over time would be expected.

The formation of gaseous ${ }^{14} \mathrm{C}$-bearing carbon compounds during the corrosion of irradiated steel was previously studied by de Visser-Týnová et al. (2018). These authors identified ${ }^{14} \mathrm{CH}_{4}$ as the main gaseous carbon compound, while smaller proportions of ${ }^{14} \mathrm{CO}$ and ${ }^{14} \mathrm{CO}_{2}$ were detected. The current study supports the results by de Visser-Týnová and coworkers. ${ }^{14} \mathrm{CH}_{4}$ accounts for more than $80 \%$ of the $\mathrm{TG}^{14} \mathrm{C}$ in this study and is thus the predominant gaseous ${ }^{14} \mathrm{C}$-bearing compound. ${ }^{14} \mathrm{C}_{2} \mathrm{H}_{6},{ }^{14} \mathrm{C}_{3} \mathrm{H}_{8}$, and ${ }^{14} \mathrm{CO}$ are only minor contributors to the $\mathrm{TG}^{14} \mathrm{C}$ with proportions of $\sim 2 \%, \sim 1 \%$, and $\sim 2 \%$, respectively, assuming that each carbon compound carried only one ${ }^{14} \mathrm{C}$ atom (Fig. 3b). It should be noted that there is still a discrepancy between the sum of ${ }^{14} \mathrm{C}$ carried by the $\mathrm{HCs}$ and $\mathrm{CO}$ and the $\mathrm{TG}^{14} \mathrm{C}$, suggesting the presence of one or more additional, as yet unidentified ${ }^{14} \mathrm{C}$ bearing compounds at low concentrations (Fig. 3b).

De Visser-Týnová et al. (2018) also observed that ${ }^{14} \mathrm{C}$ was mainly released into solution as ${ }^{14} \mathrm{C}$-bearing carbonate. The fraction of ${ }^{14} \mathrm{C}$ released into the gas phase was comparatively small ( $<6 \%$ of total ${ }^{14} \mathrm{C}$ released). The fraction of gaseous ${ }^{14} \mathrm{C}$ compared to ${ }^{14} \mathrm{C}$ released into solution (CAs, carbonate) is significantly higher in this study (Fig. 2). The higher fraction of ${ }^{14} \mathrm{C}$ in the liquid phase compared to the gas phases in the study of de Visser-Týnová et al. (2018) could be explained by the preferential formation of oxygenated ${ }^{14} \mathrm{C}$-bearing carbon compounds as a consequence of the higher dose rate of irradiated steel. The total dose rate of irradiated steel used in this study was about two orders of magnitude lower ( $0.21 \mathrm{~Gy} / \mathrm{h}$ ) than the one of the material used by de Visser-Týnová et al. (2018) ( $20 \mathrm{~Gy} / \mathrm{h}$ ) (Mibus et al., 2018). The higher dose rate implies higher concentrations of oxidizing radicals in solution generated by radiolysis at the interface with steel, which favors the formation of oxygenated, water-soluble carbon compounds such as CAs or carbonate.

Studies with non-irradiated iron powders have shown that the concentration of HCs released into the gas phase tends to decrease with increasing numbers of $\mathrm{C}$ atoms according to an Anderson-Schulz-Flory (ASF) product distribution (Cvetković et al., 2018a; Deng et al., 1997; Guillemot et al., 2020a). The latter distribution suggests a Fischer-Tropsch (F-T) type mechanism leading to the formation of HCs on the metal surface. This general trend also applies to the current study with irradiated steel, as it shows that ${ }^{14} \mathrm{CH}_{4}$ is the predominant $\mathrm{HC}$ formed during the corrosion of ${ }^{14} \mathrm{C}$ containing stainless steel. However, in contrast to previous studies with non-irradiated iron powders (Cvetković et al., 2018a; Guillemot et al., 2020a), the HCs with higher molecular weights were quantified only in trace amounts. We suspect that the difference in speciation is due to the different chemical forms of the carbon in the materials used. The nonirradiated iron powders were produced by the reduction of $\mathrm{Fe}(\mathrm{CO})_{5}$ with $\mathrm{H}_{2}$ and had a higher $\mathrm{C}$ content with the $\mathrm{C}$ probably in the chemical form of carbide. Iron carbides have multiple stoichiometries (Cotton and Wikinson, 1980), such as $\mathrm{Fe}_{3} \mathrm{C}, \mathrm{Fe}_{7} \mathrm{C}_{3}$, and $\mathrm{Fe}_{2} \mathrm{C}$, with $\mathrm{Fe}_{3} \mathrm{C}$ being the main chemical form in steel (Davis, 1998). The structure of iron carbides consists of carbon chains running through distorted metal lattices (Cotton and Wikinson, 1980), which can lead to the formation of HCs with higher molecular weights. In contrast, ${ }^{14} \mathrm{C}$ is produced by the activation of ${ }^{14} \mathrm{~N}$ impurities in steel via the nuclear reaction ${ }^{14} \mathrm{~N}(\mathrm{n}, \mathrm{p}){ }^{14} \mathrm{C}$, where $\mathrm{N}$ is accommodated in the interstices of metal crystals or bound by a substitutional solid solution replacing a solvent atom in a lattice position (Davis, 1998). Therefore, ${ }^{14} \mathrm{C}$ may be uniformly distributed as single species in the metal matrix, which explains the release of ${ }^{14} \mathrm{C}$ during corrosion mainly as single carbon species, i.e. ${ }^{14} \mathrm{CH}_{4}$.

\subsection{Implications for the safe disposal of radioactive waste}

Knowledge of the ${ }^{14} \mathrm{C}$ speciation is of paramount importance in the context of an overall assessment of the pathways of ${ }^{14} \mathrm{C}$ migration from the EBS of the DGR into the surrounding host rock and ultimately into the environment. The present study leads to the following conclusions with regards to application in safety assessment:

1. The corrosion of steel in cement-type solutions with a $\mathrm{pH} 12.5$, and thus the release of ${ }^{14} \mathrm{C}$, is a very slow process (corrosion rate of $1 \mathrm{~nm} / \mathrm{yr}$ ), while even lower rates have been determined for steel embedded in cementitious material ( $<1 \mathrm{~nm} / \mathrm{yr}$ ) (Senior et al., 2020; Senior et al., 2021).

2. The amount of ${ }^{14} \mathrm{C}$ released as water-soluble oxygenated carbon compounds (e.g. CAs, carbonate) is very low (i.e. $\sim 0.003 \%$ of the initial ${ }^{14} \mathrm{C}$ inventory of the irradiated steel samples used in this study) and occurs in the very early phase of corrosion by rapid release from the oxide layer of the steel upon contact with solution. There is no evidence that the amount of water-soluble oxygenated carbon compounds increases over time as a result of corrosion. The water-soluble organic ${ }^{14} \mathrm{C}$ fraction migrates from the EBS into the surrounding host rock by diffusion.

3. There is evidence that the proportion of ${ }^{14} \mathrm{C}$ released as ${ }^{14} \mathrm{CO}_{3}^{2-}$ in the early phase of anoxic corrosion of irradiated steel and at the given low dose rate of the material is slightly less than that released as water-soluble organic ${ }^{14} \mathrm{C}$-bearing compounds. ${ }^{14} \mathrm{CO}_{3}^{2-}$ is strongly retained in the cementitious near field by precipitation as calcium carbonate or by isotopic exchange with $\mathrm{CO}_{3}^{2-}$ from calcium carbonate (Allard et al., 1981; Bayliss et al., 1988) and therefore ${ }^{14} \mathrm{C}$ decays within the repository. 
4. The initial amounts of ${ }^{14} \mathrm{C}$-bearing CAs and presumably also ${ }^{14} \mathrm{CO}_{3}^{2-}$ released into the solution depend on whether and to what extent the irradiated metal parts have been exposed to oxic conditions (e.g. storage in air, radiolysis-induced oxidation in nuclear power plants, etc.) before their final disposal.

5. ${ }^{14} \mathrm{CH}_{4}$ is the main gaseous ${ }^{14} \mathrm{C}$ carrier produced during anoxic corrosion of irradiated steel and is capable of carrying ${ }^{14} \mathrm{C}$ from the EBS of a DGR into the environment. The release of ${ }^{14} \mathrm{C}$ into the gas phase occurs consistently with $\mathrm{H}_{2}$ production at the appropriate corrosion rate $(1 \mathrm{~nm} / \mathrm{yr}$ in this study).

\section{Conclusions}

AMS-based analytical methods enabled the determination of ultra-low ${ }^{14} \mathrm{C}$ concentrations in a corrosion experiment with irradiated stainless steel (i.e. in the pico- to femtomolar range). Measurements of the total ${ }^{14} \mathrm{C}$ contents $\left(\mathrm{d}-\mathrm{TO}^{14} \mathrm{C}, \mathrm{p}-\mathrm{TO}^{14} \mathrm{C}, \mathrm{TI}^{14} \mathrm{C}\right.$, $\mathrm{TG}^{14} \mathrm{C}$ ) and individual ${ }^{14} \mathrm{C}$ bearing carbon compounds by CSRA in solution and the gas phase show the rapid release of aqueous ${ }^{14} \mathrm{C}$-bearing carbon species in the early phase of the corrosion process (within $\sim 30$ days) and constant total inorganic $\left(\mathrm{TI}^{14} \mathrm{C}\right)$ and organic ${ }^{14} \mathrm{C}\left(\mathrm{d}\right.$ - and $\mathrm{p}-\mathrm{TO}^{14} \mathrm{C}$ ) contents in solution after the rapid release. About $40 \%$ of the $\mathrm{TO}^{14} \mathrm{C}$ is attributed to the presence of small ${ }^{14} \mathrm{C}$-bearing CAs up to $\mathrm{C} 3$, while the remaining fraction has not yet been identified. $\mathrm{TI}^{14} \mathrm{C}$ is about a factor of 3 lower than the $\mathrm{d}-\mathrm{TO}^{14} \mathrm{C}$. In contrast, the total ${ }^{14} \mathrm{C}$ content in the gas phase $\left(\mathrm{TG}^{14} \mathrm{C}\right)$ increases over time concurrently with $\mathrm{H}_{2}$ production and consistent with the corrosion of stainless steel at a rate of $1 \mathrm{~nm} / \mathrm{yr} .{ }^{14} \mathrm{CH}_{4}$ is the predominant gaseous species contributing $\sim 80 \%$ of the $\mathrm{TG}^{14} \mathrm{C}$, while other ${ }^{14} \mathrm{C}$-bearing gaseous species $\left({ }^{14} \mathrm{CO}\right.$, ${ }^{14} \mathrm{C}_{2} \mathrm{H}_{6}$ and ${ }^{14} \mathrm{C}_{3} \mathrm{H}_{8}$ ) are present only in small amounts. Therefore, modeling of ${ }^{14} \mathrm{C}$ release from a DGR should take into account that most of the ${ }^{14} \mathrm{C}$ is likely released in gaseous form. In contrast, the amount of ${ }^{14} \mathrm{C}$ released as water-soluble ${ }^{14} \mathrm{C}$ is comparatively small. A total of $0.0061 \%$ of the initial ${ }^{14} \mathrm{C}$ inventory of the irradiated steel samples was released into the solution and gas phase during 1637 days of corrosion in anoxic alkaline conditions. Assuming that the water-soluble ${ }^{14} \mathrm{C}$ fraction does not increase with time and that corrosion proceeds at a rate of $1 \mathrm{~nm} / \mathrm{yr}$, it takes $\sim 1.5 \times 10^{5}$ years for the remaining ${ }^{14} \mathrm{C}$ inventory of the irradiated steel samples to be released into the gas phase. Considering the half-life of ${ }^{14} \mathrm{C}$ $\left(t_{1 / 2}=5700\right.$ years $)$, which is short compared to the predicted release time, the ${ }^{14} \mathrm{C}$ inventory of irradiated steel and thus the contribution of ${ }^{14} \mathrm{C}$ to the dose release from a DGR will steadily decrease with time due to the radioactive decay.

\section{CRediT authorship contribution statement}

Typhaine Guillemot: Validation, Formal analysis, Investigation, Data curation, Writing - original draft, Visualization. Gary Salazar: Methodology, Software, Investigation, Writing - review \& editing. Martin Rauber: Methodology, Investigation, Writing - review \& editing. Dominik Kunz: Methodology, Investigation. Sönke Szidat: Validation, Resources, Writing - review \& editing, Project administration. Erich Wieland: Conceptualization, Validation, Writing - review \& editing, Supervision, Project administration, Funding acquisition.

\section{Declaration of competing interest}

The authors declare that they have no known competing financial interests or personal relationships that could have appeared to influence the work reported in this paper.

\section{Acknowledgments}

Partial financial support for this project was provided by swissnuclear (Project title: "Investigation of the chemical speciation of ${ }^{14} \mathrm{C}$ released from irradiated steel") and by the National Cooperative for the Disposal of Radioactive Waste (Nagra), Switzerland. Partial funding was received from the
European Union's European Atomic Energy Community's (Euratom) Seventh Framework Programme FP7/ 2007-2013 under grant agreement no. 604779 , the CAST project. Specific tasks within this project have been developed in co-operation with Brechbühler AG (Schlieren, Switzerland). The innovative technical developments and the valuable contributions to the project by Peter Pichler, Philippe Mottay and Benjamin Oberlin (all Brechbühler AG) are gratefully acknowledged. We would like to thank the NPP Gösgen for providing the irradiated steel nuts, Ines GüntherLeopold, Matthias Martin and Robin Grabherr (all PSI) for processing the material and the preparation of small specimens for laboratory experiments, as well as Dorothea Schumann and Tanja Stowasser (both PSI) for determining the ${ }^{14} \mathrm{C}$ inventory of the steel nuts. Thanks are extended to Jan Tits and Marcus Keller (both PSI) for their support during construction of the reactor and Andreas Lagotzki (PSI) for calculating the dose rate of the material.

\section{Appendix A. Supplementary data}

Supplementary data to this article can be found online at https://doi. org/10.1016/j.scitotenv.2021.152596.

\section{References}

Allard, B., Torstenfelt, B., Andersson, K., 1981. Sorption studies of $\mathrm{H}^{14} \mathrm{CO}_{3}^{-}$on some geological media and concrete. Mater. Res. Soc. Symp. Proc. 3, 465-473.

Bayliss, S., Ewart, F.T., Howse, R.M., Smith-Briggs, J.L., Thomason, H.P., Willmott, A., 1988. The solubility and sorption of lead-210 and carbon-14 in a near-field environment. Mater. Res. Soc. Symp. Proc. 112, 33-42.

Chimi, Y., Kitsunai, T., Kasahara, S., Chatani, K., Koshiishi, M., Nishiyama, Y., 2016. Correlation between locally deformed structure and oxide film properties in austenitic stainless steel irradiated with neutrons. J. Nucl. Mater. 475, 71-80.

Cotton, F.A., Wikinson, G., 1980. Advanced Inorganic Chemistry. fourth edition. WileyInterscience, New York.

Cvetković, B., Rothardt, J., Buttler, A., Kunz, D., Schlotterbeck, G., Wieland, E., 2018a. Formation of low-molecular-weight organic compounds during anoxic corrosion of zero-valent iron. Environ. Eng. Sci. 35, 447-461.

Cvetković, B., Salazar, G., Kunz, D., Szidat, S., Wieland, E., 2018b. Analysis of C-14-bearing compounds released by the corrosion of irradiated steel using accelerator mass spectrometry. Analyst 143, 3059-3067.

Cvetković, B.Z., Salazar, G., Kunz, D., Tits, J., Szidat, S., Wieland, E., 2018c. Quantification of dissolved organic C-14-containing compounds by accelerator mass spectrometry in a corrosion experiment with irradiated steel. Radiocarbon 60, 1711-1727.

Davis, J.R., 1998. Metals Handbook Vol 1: Properties and Selection: Irons, Steels, and Highperformance Alloys. American Society of Metals, Materials Park OH 44073, USA.

Deng, B.L., Campbell, T.J., Burris, D.R., 1997. Hydrocarbon formation in metallic iron/water systems. Environ. Sci. Technol. 31, 1185-1190.

Diomidis, N., 2014. Scientific Basis for the Production of Gas due to Corrosion in a Deep Geological Repository. Nagra Working Report NAB 14-21. Nagra, Wettingen, Switzerland.

Guillemot, T., Cvetković, B.Z., Kunz, D., Wieland, E., 2020a. Processes leading to reduced and oxidised carbon compounds during corrosion of zero-valent iron in alkaline anoxic conditions. Chemosphere 250, 126230.

Guillemot, T., Salazar, G., Cvetković, B.Z., Kunz, D., Szidat, S., Wieland, E., 2020b. Determination of ultra-low concentrations of gaseous C-14-bearing hydrocarbons produced during corrosion of irradiated steel using accelerator mass spectrometry. Analyst 145, 7870-7883.

Guillemot, T., Cvetković, B.Z., Kunz, D., Salazar, G., Rauber, M., Szidat, S., Wieland, E., 2021. Development of Analytical Methods for the Detection of ${ }^{14} \mathrm{C}$-bearing Carbon Compounds at Ultra-low Concentrations. Nagra Working Report NAB 21-03. Nagra, Wettingen, Switzerland.

Hanbury, R.D., Was, G.S., 2019. Oxide growth and dissolution on 316L stainless steel during irradiation in high temperature water. Corros. Sci. 157, 305-311.

Ishikawa, T., Kondo, Y., Yasukawa, A., Kandori, K., 1998. Formation of magnetite in the presence of ferric oxyhydroxides. Corros. Sci. 40, 1239-1251.

Jelinek, J., Neufeld, P., 1982. Kinetics of hydrogen formation from mild-steel in water under anaerobic conditions. Corrosion 38, 98-104.

Johnson, L., Schwyn, B., 2008. Proceedings of a Nagra/RWMC Workshop on the Release and Transport of C-14 in Repository Environments. Nagra Working Report NAB 08-22. Nagra, Wettingen, Switzerland.

Kaneko, S., Tanabe, H., Sasoh, M., Takahashi, R., Shibano, T., Tateyama, S., 2003. A study on the chemical forms and migration behavior of carbon-14 leached from the simulated hull waste in the underground condition. Mater. Res. Soc. Symp. Proc. 757, 621-626.

Mibus, J., Diomidis, N., Wieland, E., Swanton, S.W., 2018. Release and speciation of C-14 during the corrosion of activated steel in deep geological repositories for the disposal of radioactive waste. Radiocarbon 60, 1657-1670.

Nagra, 2014a. Sicherheitstechnischer Bericht zu SGT-Etappe 2: Sicherheitstechnischer Vergleich und Vorschlag der in Etappe 3 weiter zu untersuchenden geologischen Standortgebiete. Nagra Technical Report 14-01. Nagra, Wettingen, Switzerland.

Nagra, 2014b. Modellhaftes Inventar für radioaktive Materialien MIRAM 14. Nagra Technical Report 14-04. Nagra, Wettingen, Switzerland. 
Nagra, 2016. Waste Management Programme 2016 of the Waste Producers. Nagra Technical Report NTB 16-01E. Nagra, Wettingen, Switzerland.

Nuclear Decommissioning Authority, 2012. Geological Disposal - Carbon-14 Project - Phase 1 Report. Technical Report NDA/RWMD/092. Harwell, Didcot, United Kingdom.

Raiman, S., Was, G.S., 2017. Accelerated corrosion and oxide dissolution in 316L stainless steel irradiated in situ in high temperature water. J. Nucl. Mater. 493, 207-218.

Rauber, M., 2018. Compound-specific Radiocarbon Analysis of Aerosols. Faculty of Science. University of Bern, Bern, Switzerland Master thesis.

Sakuragi, T., Yoshida, S., Kato, O., Tateishi, T., 2016. Study of stainless steel corrosion by hydrogen measurement under deoxygenated, low-temperature and basic repository conditions. Prog. Nucl. Energy 87, 26-31.

Salazar, G., Zhang, Y.L., Agrios, K., Szidat, S., 2015. Development of a method for fast and automatic radiocarbon measurement of aerosol samples by online coupling of an elemental analyzer with a MICADAS AMS. Nucl. Instrum. Methods Phys. Res., Sect. B 361, 163-167.

Schumann, D., Stowasser, T., Volmert, B., Günther-Leopold, I., Linder, H., Wieland, E., 2014. Determination of the C-14 content in activated steel components from a neutron spallation source and a nuclear power plant. Anal. Chem. 86, 5448-5454.

Senior, N.A., Martino, T., Diomidis, N., Gaggiano, R., Binns, J., Keech, P., 2020. The measurement of ultra low uniform corrosion rates. Corros. Sci. 176, 108913.

Senior, N.A., Martino, T., Gaggiano, R., Diomidis, N., 2021. The corrosion of mild and stainless steel in alkaline anaerobic conditions representing the Belgian "supercontainer" concept and the Swiss L/ILW repository. Mater. Corros. 72, 67-74.

Smart, N.R., 2009. Corrosion behavior of carbon steel radioactive waste packages: a summary review of Swedish and U.K. research. Corrosion 65, 195-212.

Spinks, J.W.T., Woods, R.J., 1990. An Introduction to Radiation Chemistry. 3rd ed. John Wiley and Sons, New York.

Swanton, S.W., Baston, G.M.N., Smart, N.S., 2015. Rates of Steel Corrosion and Carbon-14 Release From Irradiated Steel - State of the Art Review. CAST WP2 Deliverable D 2.1. European Union, Brussels.

Szidat, S., Salazar, G.A., Vogel, E., Battaglia, M., Wacker, L., Synal, H.-A., Türler, A., 2014. C14 analysis and sample preparation at the new Bern laboratory for the analysis of radiocarbon with AMS (LARA). Radiocarbon 56, 561-566.
Tamaura, Y., Ito, K., Katsura, T., 1983. Transformation of $\gamma-\mathrm{FeO}(\mathrm{OH})$ to $\mathrm{Fe}_{3} \mathrm{O}_{4}$ by absorption of iron(II) ion on $\gamma$-FeO(OH). J. Chem. Soc. Dalt. Trans. 189-194.

Varlet, V., Smith, F., Augsburger, M., 2013. Indirect hydrogen analysis by gas chromatography coupled to mass spectrometry (GC-MS). J. Mass Spectrom. 48, 914-918.

de Visser-Týnová, E., Swanton, S.W., Williams, S.J., Stijkel, M.P., Walker, A.J., Otlet, R.L., 2018. C-14 release from irradiated stainless steel. Radiocarbon 60, 1671-1681.

Wacker, L., Fahrni, S.M., Hajdas, I., Molnar, M., Synal, H.A., Szidat, S., Zhang, Y.L., 2013. A versatile gas interface for routine radiocarbon analysis with a gas ion source. Nucl. Instrum. Methods Phys. Res. Sect. B 294, 315-319.

Was, G., 2017. Fundamentals of Radiation Materials Science. 2nd ed. Springer-Verlag, Berlin Heidelberg.

Wieland, E., Hummel, W., 2015. Formation and stability of C-14-containing organic compounds in alkaline iron-water systems: preliminary assessment based on a literature survey and thermodynamic modelling. Mineral. Mag. 79, 1275-1286.

Wieland, E., Cvetković, B.Z., Kunz, D., Salazar, G., Szidat, S., 2017. Identification and formation of carbon-14 containing organic compounds during anoxic corrosion of activated steel in alkaline conditions. 16th International High-Level Radioactive Waste Management Conference (IHLRWM 2017), Charlotte, NC, USA.

Wieland, E., Cvetković, B., Kunz, D., Salazar, G., Szidat, S., 2018. Carbon-14 speciation during anoxic corrosion of activated steel in a repository environment. Atw-Int. J. Nucl. Power 63, 34-39.

Yamashita, Y., Tanabe, H., Sakuragi, T., Takahashi, R., Sasoh, M., 2014. C-14 release behavior and chemical species from irradiated hull waste under geological disposal conditions. Mater. Res. Soc. Symp. Proc. 1665, 187-194.

Yim, M.-S., Caron, F., 2006. Life cycle and management of carbon-14 from nuclear power generation. Prog. Nucl. Energy 48, 2-36.

Zhao, Y., Li, Y., Wu, Q., Qi, W., Zhang, T., Wang, F., 2021. Effect of thermal aging and irradiation on the electrochemical and passivation behavior of 308L stainless steel in simulated pressurized water reactor environment. Mater. Lett. 286, 129157. 